ARTIGOS/

ARTICLES 


\title{
DESCONFORTO E INVISIBILIDADE: REPRESENTAC̣ÕES SOBRE RELAÇÕES DE GÊNERO ENTRE SINDICALISTAS DOCENTES ${ }^{1}$
}

\author{
Márcia Ondina Vieira Ferreira* \\ Faculdade de Educação/UFPel
}

\begin{abstract}
RESUMO: Analisam-se as representações sobre relações de gênero na educação e as trajetórias sindicais de diretoras/es do $24^{\circ}$ Núcleo do CPERS/SINDICATO (Centro dos Professores do Estado do Rio Grande do Sul - Sindicato dos Trabalhadores em Educação). No referencial, recuperam-se aspectos da constituição da docência que interferem nas representações sobre esse ofício: feminização, proletarização e sindicalização, bem como a fragilidade, nos sindicatos e na academia, das discussões sobre o impacto das relações de gênero no trabalho docente. Em termos empíricos, examinam-se: a escolarização dos sujeitos como estratégia familiar de ascensão social; as resistências a abordar o tema das relações de gênero; a tendência das mulheres a criticar comportamentos masculinos, em classe e na militância; e a dos homens de valorizar a atividade feminina.
\end{abstract}

Palavras-chave: Docência e Relações de Gênero; Trabalho Docente; Sindicalismo Docente

\section{DISCOMFORT AND INVISIBILITY: THE REPRESENTATIONS OF GENDER RELATIONS OF UNIONIZED TEACHERS}

ABSTRACT: This paper analyzes the representations of gender relations in education and the trajectories of CPERS/SINDICATO (the Teachers' Union - 24th Section) board members. It takes up discussions on issues such as teaching feminization, proletariatization, and union affiliation and emphasizes that the discussions on the impact of gender relations on the teachers' work carried out at unions and the academia are characterized by a certain weakness. The following aspects are examined as well: schooling as a familial strategy of social ascension, resistance to talking about gender relations, tendency of women to criticize male behavior in class and in labor activism, and the tendency of men to valorize female activities.

Keywords: Gender; Teachers' Work; Teachers' Union

* Professora do Programa de Pós-Graduação em Educação da Faculdade de Educação/UFPel. Coordenadora do Grupo de Pesquisas "Processo de Trabalho Docente".E-mail: marciaof@ufpel.edu.br 
Como, de fato, não experimentar um sentimento de inquietação no momento de tornar públicas conversas privadas, confidências recolhidas numa relação de confiança que só se pode estabelecer na relação entre duas pessoas? Sem dúvida, todos os nossos interlocutores aceitaram confiar-nos o uso que seria feito de seus depoimentos. Mas jamais houve um contrato tão carregado de exigências tácitas como um contrato de confiança (BOURDIEU, 1997, p. 9).

\section{OBJETIVOS E PROCEDIMENTOS METODOLÓGICOS DO TRABALHO}

Neste texto, apresento um recorte de uma pesquisa cujo principal propósito foi investigar a participação de homens e mulheres num sindicato que congrega docentes, especialistas e servidores/as técnicoadministrativos/as, no âmbito do ensino básico público do Rio Grande do Sul: o Centro dos Professores do Estado do Rio Grande do Sul Sindicato dos Trabalhadores em Educação (CPERS/SINDICATO). Foram enfocadas as relações de gênero pela convicção de que, primeiro, são praticamente negadas na maioria das esferas sociais, incluindo a área educacional e, mesmo, a acadêmica; segundo, constituem uma ferramenta indispensável para se compreender diversos processos sociais em educação, entre eles o trabalho docente. Na referida pesquisa, foram sistematizadas informações sobre o perfil e a participação por sexo no CPERS, incluindo a participação em instâncias de direção da entidade. Além disso, no plano da percepção sobre proletarização/profissionalidade da docência, perseguiu-se a idéia da sindicalização como indicador de uma das identidades docentes.

Especificamente aqui, buscarei sintetizar um dos enfoques da análise, relativo às concepções sobre relações de gênero na educação e entre o professorado, explicitadas por dois diretores e cinco diretoras do $24^{\circ}$ Núcleo do referido sindicato, bem como as trajetórias desenvolvidas para que se tornassem sindicalistas. As informações foram obtidas por entrevistas semi-estruturadas, realizadas com seis docentes e uma servidora técnico-administrativa, de um total de nove membros da diretoria do Núcleo (Gestão 2002/2005). As entrevistas foram realizadas entre novembro de 2002 e maio de 2003.

É necessário esclarecer que o Centro dos Professores do Estado do Rio Grande do Sul foi transformado em Sindicato em 1989, filiandose à Central Única dos Trabalhadores (CUT) em 1996. Sua criação remonta a 1945, chamado, então, de Centro dos Professores Primários Estaduais. Está composto por 42 Núcleos de caráter regional, organizações de base que respondem à divisão oficial das estruturas de adminis- 
tração educacional do estado. Assim, o $24^{\circ}$ Núcleo atua nos mesmos municípios administrados pela $5^{\text {a }}$ Coordenadoria Regional de Educação ( $\left.5^{\mathrm{a}} \mathrm{CRE}\right)$, ambos sediados em Pelotas.

\section{ALGUMAS REFERÊNCIAS TEÓRICAS}

Nesta seção, serão sintetizadas referências teóricas para a análise das relações de gênero nos sindicatos que congregam o professorado. É uma recuperação bastante exploratória, considerando a variedade de fontes e focos de exame que podem ser utilizados. Em primeiro lugar, julguei que seria importante abordar a consolidação dessa categoria ocupacional no transcorrer dos séculos. Isso significa vê-la como um grupo que adquire características bem-definidas, entre elas a feminização e a proletarização.

Mas a feminização não apresenta apenas implicações na esfera econômica; também no plano das representações (culturais), encontramos um veio interessante de análises sobre a docência, e que nesse artigo adquire importância central.

Por outra parte, ao reunir feminização e proletarização, chegamos a outro fenômeno bastante significativo, especialmente a partir das últimas décadas do século passado: um processo de sindicalização da docência muito próximo ao que acontece com os trabalhadores manuais. Como se produzem as relações de gênero em um ambiente constituído, $a$ priori, para se deparar com questões de classe? A feminização do professorado tem sido incorporada, como elemento de análise, pelos sindicatos docentes?

Esses serão alguns dos temas esboçados a seguir.

\subsection{Feminização e proletarização da docência: Representações sobre a docência}

Como e por que o magistério transforma-se em trabalho considerado "de mulher"? Para o que me interessa destacar, entre os vários fatores que permitiram a feminização do magistério é possível citar o aparecimento de ocupações mais rendosas, à época da industrialização, ocupadas por homens, o processo de extensão da escola estatal e a própria pressão das mulheres para sair ao espaço público (ALMEIDA, 2007; ARAÚJO, 1990; LOURO, 2001; NÓVOA, 1991; TAMBARA, 2002). Ensinar passou a ser tarefa de quem não era considerado sustentáculo econômico em primeiro lugar, mas também social - da família: mulheres que, por sua vez, modificaram a origem de classe do professorado. Para 
possuir educação suficiente para ensinar - não necessariamente conbecimentos -, em princípio deveriam provir de setores das classes "médias". Contudo, esse espaço ocupado pelas mulheres não lhes foi concedido sem disputas (ALMEIDA, 1998; LOURO, 2001; VILLELA, 2000); fez-se necessária uma forte transformação na principal imagem da docência, agora compreendida como uma extensão do trabalho doméstico, realizado por quem é por ele responsável e no período de tempo que não o compro-mete.

Como um parêntese, assinalemos a concordância de vários autores sobre as conexões entre classe social e gênero para a interpretação da situação de certas ocupações (BOURDIEU, 1999), como a docência (APPLE, 1987; FERNÁNDEZ ENGUITA; SAN ROMÁN GAGO, 2001). O próprio termo semiprofissão está associado à feminização de algumas ocupações (GUERRERO SERÓN, 1996), mesmo que não concordemos com os motivos utilizados para explicá-lo. Parkin (1984), por exemplo, rebela-se quanto à idéia de que as mulheres têm sido aceitas em algumas ocupações porque seriam mais submissas, como afirmam Simpson; Simpson (1999), o que Parkin chama de "teoria machista da profissionalização".

Para Louro, no texto citado, a feminização do magistério não levou necessariamente a baixos salários, mais bem justificon que se pagasse menos e pedisse pouco por esse trabalho. Ademais, foi construída uma imagem de trabalho feminino da qual, hoje, os ofícios tidos como femininos não podem escapar: ocupam-se do "cuidado", e quem cuida está "vocacionado/a". Vamos abordar essas idéias com mais vagar.

Para tanto, é preciso inicialmente dizer que estou recuperando a idéia de representações como criações no campo da cultura, isto é, não são atributos intrínsecos àquilo de que se fala. Mesmo as representações majoritárias, aquelas instituídas pelos sujeitos que têm o poder de representar, constroem a realidade que dizem, meramente, "representar", "refletir" (HALL, 1997; SILVA, 1996, 1999, 2000). Assim, nos embates a respeito, iniciados desde meados do século XIX, vêm circulando várias imagens: de mulher, de mulher docente e simplesmente de "docente". O papel da escola também se modifica, pelas exigências do modo de produção e pelas reivindicações de extensão da escolarização. Já no século $\mathrm{XX}$, o magistério era majoritariamente feminino. No Brasil, o desenvolvimento das teorias educacionais implicou exigências profissionais que engendraram diferentes representações de docentes. Louro, anteriormente citada, resume: as docentes foram chamadas de "professorinhas", "tias" e "trabalhadoras da educação". 
Desde as últimas décadas do século $\mathrm{XX}$, assistimos ao acirramento da diminuição do Estado em matéria de sustento econômico da educação e de outras de suas obrigações, mas não a um encolhimento de seu controle. Para muitos, isso desencadeou um procedimento de divisão e de reorganização do processo de trabalho docente, sustentado, no campo pedagógico, por teorias de caráter tecnicista. Vou me abster, aqui, da discussão aprofundada de estudos sobre desqualificação do professorado e sua alegada proletarização; posso citar as revisões de Ferreira (2002) ou Hypolito (1997). Entretanto, é inegável que essa etapa inaugura nova representação de docência, um movimento contraditório que articula a necessidade de "profissionalização do ensino" com um processo de "proletarização do professorado": este, ao mesmo tempo, reivindica profissionalização e fortalece organizações à semelhança das entidades de trabalhadores manuais, os sindicatos.

No caso do nosso e de outros países latino-americanos, é significativo o fato de que as associações docentes adquiriram caráter sindical em conjunto com lutas sociais em processos de democratização, lançando às ruas outras imagens de docentes: militantes e grevistas. Associadas a uma possível identidade "trabalhadora", essas são as mais recentes representações circulantes, embora talvez já encontremos uma geração de jovens docentes que não se identifiquem com as mesmas (FERREIRA, 2002; VIANNA, 1996).

Por fim, faz sentido indagar o quanto a reflexão sobre as representações da docência - como as influências da imagem feminina sobre o status da ocupação - habita o cenário sindical. Segundo Costa,

... os sindicatos e associações de docentes têm articulado suas reivindicações

e lutas ainda distanciados dos debates contemporâneos que colocam as políticas de representação como centrais nos movimentos sociais pela afirmação de identidades negadas e/ou pela contestação de identidades estrategicamente instituídas (1999, p. 117).

\subsection{Da feminização à análise das relações de gênero: os mundos da educação e sindical}

Como foi dito anteriormente, há dúvidas sobre a existência de reflexão, nos sindicatos docentes, no que tange às representações da docência como trabalho feminino. Se concordarmos que os sindicatos são exemplos de organizações criadas a partir da categoria classe social, entenderemos por que eles apresentam dificuldade de trabalhar com outras categorias de análise. O que está na base dessa compreensão é a idéia de que o sujeito de classe é universal, portanto deveria dar conta da 
totalidade das problematizações e reivindicações levadas a efeito pelos sindicatos, evitando reconhecer que esse sujeito expressa interesses de grupo.

Numa crítica a esta perspectiva, Parkin (1984), seguindo Weber e seu conceito de fechamento social ${ }^{2}$, afirma que os sindicatos excluem grupos sociais não-majoritários, como os grupos étnicos e as mulheres. Vianna diz (com base em Leila Blass) que "existe um modelo masculino de sindicato, um modelo universalista de marca masculina que embasa a organização operária" (2001, p. 109). Por fim, Cappellin denuncia que as organizações sindicais, embora desenvolvendo um discurso sobre o tema do trabalho tendo em mente a idéia da igualdade, "foram construídas com a participação dos homens e das mulheres, graças ao debate sobre o trabalho - muitas vezes assexuado - com uma imagem produtivista de suas vidas, contruindo uma estrutura de representação predisposta pelos homens e para os homens" (1994, p. 273).

Mas, antes de aprofundar esse tema, torna-se necessário explicar o raciocínio utilizado nesta seção: quando passamos (1) do sujeito desgenerificado à (2) feminização e ao (3) estudo das relações de gênero, na docência, na educação e na sociedade, não muda apenas nosso objeto de estudo, mas também mudam nossos "óculos" para seu estudo, isto é, nossos referenciais e metodologias.

Assim, só muito recentemente a presença das mulheres no mundo do trabalho vem sendo examinada em sua especificidade - isto é, quando se deixa de ver o trabalho feminino como simples subproduto do trabalho em geral. Seus antecedentes provêm da própria discussão de feministas sobre a divisão sexual do trabalho. Por sua parte, os sindicatos operários tiveram bastante dificuldade de incorporar o trabalho das mulheres em sua agenda de discussão e de lutas. Como exemplo brasileiro, em 1977 o Sindicato de Metalúrgicos de São Bernardo assim se manifestava a respeito de modificação na legislação que incluiria as mulheres no trabalho noturno, dizendo que não há

nenhuma razão que justifique a intensificação da exploração da mulher pelo aumento de sua jornada de trabalho e colocando-a no exercício de atividades inadaptadas à sua constituição física, num momento em que os homens lutam por melhorar suas condições de emprego e seus salários. É como se enviassem as mulheres à fábrica e os maridos ficassem em casa. Uma estúpida inversão de papéis (apud SOUZA-LOBO, 1991, p. 67-8).

Como se vê, impera o citado processo de fechamento social (para baixo, ou fechamento de exclusão), realizado pelo sindicato em 
relação às mulheres, sob a justificativa de diferentes papéis sexuais. Mas, junto a essa dificuldade de incorporar as questões das mulheres, apresentada pelos discursos e pelas práticas sindicais, vemos que a produção sociológica também apresenta carências. Segundo Souza-Lobo - que estou tomando aqui como uma de minhas principais referências ${ }^{3}$-, “...as operárias passam a ser exclusivamente objeto específico de uma sociologia específica cujos temas e análises não são incorporados aos estudos sobre a classe operária ou o movimento operário, que permanecem exclusivamente masculinos".

Acreditamos que, na raiz dessa resistência em trabalhar a problemática classe/gênero, existem duas ordens de argumentos. De um lado subsiste uma concepção de homogeneidade de classe operária que por sua vez remete a um conceito de classe construído exclusivamente a partir do lugar na produção, como se fosse possível separar relações sociais e relações de produção (1991, p. 116-117).

E porque considera que essas não podem ser separadas, a autora ascende ao conceito de relações de gênero, que, também, é uma importante ferramenta usada mais recentemente para a compreensão dessa problemática no plano da educação e do trabalho docente. SouzaLobo assume o conceito de gênero na acepção sistematizada por Scott (1995) ${ }^{4}$, dizendo, num texto originalmente publicado em 1987: "utilizo o conceito de gênero como conjunto de representações sociais construídas a partir das condições biológicas das diferenças entre os sexos" (1991, p. 183). E acrescenta:

“(...) os itinerários de homens e mulheres não podem ser reduzidos a simples efeitos mecânicos de uma identidade cristalizada de uma vez para sempre, ou não haveria história. Daí a importância das análises que têm por objeto as práticas sociais e as instituições, onde as relações de gênero se constroem" (1991, p. 188).

E se é assim nos estudos sobre o trabalho operário, na produção brasileira sobre o trabalho docente os gêneros também são invisíveis, segundo Bruschini; Amado (1988) e Rosemberg; Amado (1992). Outras revisões, como a de Gonçalves; Gonçalves e Silva (1998) e Rosemberg (2001) indicam situação semelhante, ao examinar as relações de gênero na educação. Sintetizarei algumas características dos estudos indicados.

A maior parte dos trabalhos (realizados em cursos de pósgraduação em Educação) está inserido na palavra-chave mulher, e não em relações de gênero (são muito poucos os relativos ao gênero masculino); os trabalhos têm sido realizados em pouquíssimas instituições uni- 
versitárias de determinados estados do país, por autoras (e orientadoras) mulheres. Além disso, teses, dissertações e artigos em revistas de Educação "focalizam mais a condição feminina que o sistema educacional numa perspectiva de gênero" (ROSEMBERG, 2001, p. 47), enquanto os periódicos feministas pouco se ocupam da questão educacional.

Especialmente sobre os trabalhos publicados na página da

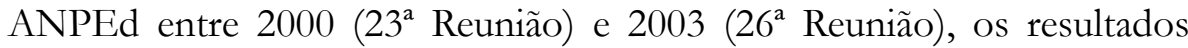
encontrados numa quinta revisão tampouco são satisfatórios. Dos 1505 trabalhos conferidos, entre todas as categorias - trabalhos encomendados, trabalhos e pôsteres apresentados nos GT's, minicursos, sessões especiais e trabalhos excedentes - "foi encontrado um total de 42 trabalhos cujos assuntos possuíam algum grau de relação com questões de gênero e/ou de sexualidades. Destes, os que possuíam como palavra-chave a expressão gênero foram 23" (FERREIRA, 2006, p. 78).

A seguir, a síntese do referencial teórico abordará as relações de gênero nos sindicatos.

\subsection{Relações de gênero e participação sindical}

A literatura consultada sobre as relações de gênero dentro dos sindicatos é significativa em suas contribuições, embora, novamente, aqui, seja escassa. Mais escassa, ainda é a análise das relações de gênero em organizações sindicais cuja base é principalmente formada por mulheres, como é o caso do professorado (VIANNA, 2001).

Retomando a idéia de que as relações de gênero nos sindicatos começa a ser discutida quando a problemática da mulher trabalhadora vem à tona, cabe dizer que a participação das mulheres na ação sindical relaciona-se com o tipo de inserção que têm no mundo do trabalho. Suas opções ocupacionais são mediadas por fatores como o estado conjugal, a idade e a escolaridade, o número de filhos e sua idade e estrutura familiar (BRUSCHINI, 1996). Ao lado disso, certos valores culturais também interferem nessas alternativas e na participação ou não, bem como no tipo de participação que as mulheres tenham na atividade sindical. Assim, dificultam-na a segunda jornada de trabalho, o machismo dos familiares, especialmente dos homens, mas também das mães (GIULANI, 2001), e a falta de domínio das "tecnologias do poder” (ALVES, 1999), “... como o palanque, um assento na mesa de negociações, o microfone nos comícios ou o discurso nas assembléias", tal como afirma Castro (1995, p. 31).

Mas a falta de protagonismo feminino não ocorre apenas no meio sindical. Historicamente, nos espaços públicos, a presença masculina 
supera em muito a feminina, sendo as decisões políticas tarefas de homens. Contudo, segundo um estudo da Comisión Económica para América Latina y el Caribe (CEPAL) (1999) sobre a participação das mulheres da América Latina e do Caribe na esfera estatal, nos partidos políticos e em organismos de representação da sociedade civil, a CUT brasileira dividia, em 1998, o $5^{\circ}$ lugar (com a Dominica Teacher's Association) em termos de número de mulheres nas direções nacionais. Foi encontrado o percentual de 30\%, o mínimo recomendado pela política de cotas. De acordo com Delgado (1998) e Pinto (2003), a política de cotas na CUT foi adotada em 1993, sendo que em 1994 foi eleita a primeira Executiva Nacional com esta composição (DELGADO, 1998).

Em termos institucionais, a Lei n. 9504/1997 determinou cota mínima de 30\% e máxima de 70\%, para qualquer um dos sexos, no caso das eleições para Câmara dos Deputados, Assembléias Legislativas Estaduais e Câmara Distrital, sendo que, para as eleições de 1998, valeram os valores de $25 \%$ e $75 \%$.

Por outro lado, e para além da política de cotas, trata-se de discutir o quanto os espaços públicos, incluindo o sindical, viabilizam ou dificultam a presença das mulheres. Estudos como o de Sartori (2001), Giulani (2001), Alves (1999), Castro (1995), Cappellin (1994), Amado; Checa (1990) e, enfim, Humphrey (1983) revelam não só que a participação feminina é mais dificultada do que a masculina, mas também nos fazem perceber que o estudo das relações de gênero deve superar constatações como essa.

Quanto à primeira constatação, cabe retomar o que já foi citado quanto ao sindicato como espaço construído para ser palco dos homens. $\mathrm{Na}$ medida em que o sujeito da classe social é considerado sujeito universal, não se torna perceptível que esse é preponderantemente masculino, não sobra espaço para a reflexão sobre particularidades. Isso pode levar a situações de desigualdade num local que, teoricamente, existe para lutar contra elas, sendo o machismo somente uma parte e certamente a menos sutil.

Entretanto - e aqui ingressamos na segunda constatação -, é preciso matizar a questão das desigualdades de gênero, para não colocar em posição dicotômica o masculino e o feminino, tornando sem sentido o próprio significado de gênero. "Masculinidade e feminilidade não são sobreponíveis (sic) respectivamente a homens e mulheres, mas são metáforas de poder e de capacidade de ação e, como tal, acessíveis a homens e mulheres" (VALE DE ALMEIDA apud SARTORI, 2001, p. 224). 
Assim, avançamos se compreendemos gênero em suas dimensões simbólicas e no plano das práticas sociais, tal como Connell (1995), Fuller (1998) e Kimmel (1998), estudiosos das masculinidades. Por masculinidade Connell entende "uma configuração de prática em torno da posição dos homens na estrutura das relações de gênero", existindo, "normalmente, mais de uma configuração desse tipo em qualquer ordem de gênero de uma sociedade" (1995, p. 188). Enfatiza, desse modo, que os gêneros não são simples contenedores de supostas características de indivíduos do sexo masculino ou do feminino, pois assim voltaríamos às definições de caráter biológico ${ }^{5}$. Connell menciona, ao menos, quatro padrões de masculinidade atualmente ${ }^{6}$ a cúmplice, a marginalizada, a subordinada e a hegemônica. Essa última é uma imagem dominante de masculinidade que expressa determinada configuração de poder - e isso deve ser frisado -, mas que, por sua vez, tampouco é fixa e a-histórica.

Esses encaminhamentos da análise sobre as relações de gênero são bastante importantes, podendo-se inclusive dizer que foi o reconhecimento da necessidade de estudar-se igualmente os homens que "colocou em evidência o caráter generificado das próprias organizações e o papel ativo das relações de trabalho tanto na construção de significados sociais de masculinidade e feminilidade, quanto na estruturação de identidades de gênero" (CARVALHO, 1998), o que é significativo no caso da docência, em especial no nível primário.

Quanto ao sindicato docente, é curioso investigar que identidades e representações de gênero nele circulam e se nele se apresenta esse viés de masculinidade hegemônica que caracteriza o sindicalismo em geral, sem, no entanto, naturalizar os sindicatos como espaços masculinos, porque neles "há outros sistemas de privilégios e exclusões tais como raça/etnicidade, idade e preferências sexuais que também filtram a participação no poder" (CASTRO, 1995).

A seguir serão destacados alguns resultados da análise empírica, focando o olhar nas representações sobre relações de gênero. Mas, primeiramente, cabe caracterizar os entrevistados. 


\section{MILITANTES DOCENTES: HOMENS E MULHERES}

\subsection{Trajetórias de inserção no sindicato docente}

Das e dos sindicalistas entrevistados, pode-se dizer que todos tiveram origem socioeconômica e cultural semelhante, tendo em vista escolaridade e ocupação dos pais. Percebe-se uma estratégia familiar visando à ascensão social por meio da educação, embora, no caso das mulheres, se destaque sua escolaridade regular e uma tendência a buscar o magistério desde cedo, mesmo que nem sempre por opção pessoal. Em vários casos, foi a interferência da família que as conduziu à docência. Já os dois homens apresentaram uma escolaridade não regular, optando pela docência tardiamente. Todos os sujeitos cursaram licenciaturas e alguns realizaram cursos em nível de especialização.

Sua atividade profissional tem sido intensa, tanto em setores direção, coordenação pedagógica, supervisão escolar, etc. - quanto em sala de aula. Quanto à faixa etária, à altura das entrevistas somente um homem estava abaixo dos 40 anos de idade, todos os demais sujeitos eram mais velhos. Havia apenas uma professora negra. Dos sete sujeitos, somente uma mulher é solteira e sem filhos.

Quanto à militância recente na diretoria do Núcleo, só a Diretora Geral tem liberação total, os/as demais trabalham nos "horários de folga da escola", se é que se pode dizer assim, dados seus regimes de trabalho (todas/os têm mais de uma matrícula no estado ou já compaginaram trabalho no estado e no município, etc.). Tentemos sistematizar sua chegada ao sindicato.

Como primeiro elemento a frisar, todas as mulheres afirmaram que sua militância começa no CPERS/SINDICATO, sendo sua ligação partidária mais "frouxa", enquanto os homens apresentam uma experiência - e/ou uma narrativa - mais enfática, relacionando partidos e demais atividades de participação político-social de maneira global, com justificativas mais causais do que casuais.

O primeiro homem apresenta um discurso sobre sua trajetória totalmente articulado, como se antecipasse possíveis perguntas. Freqüentemente, usa a primeira pessoa do plural, dando caráter mais genérico à experiência. Já o segundo destaca-se por apresentar uma participação político-social mais variada. Assinala ter sido um dos fundadores do Diretório Acadêmico de seu curso e da Associação dos Professores e Funcionários da escola municipal onde trabalhou, e daî emenda diretamente, como coisa natural, a participação no CPERS. 
Por sua vez, os relatos femininos são mais tímidos, às vezes indicam insegura aproximação ao sindicato, consolidando-se por questões afetivas; tal como cita Giulani (2001), são as relações de amizade entre colegas ou conjunturas específicas (greves, campanhas) que aproximam as mulheres dos sindicatos.

Por outro lado, talvez possamos interpretar que as mulheres não desejam usar o discurso para se destacar, ao especificar sua atuação. Elas com freqüência questionam se estão à altura das exigências dos cargos, que dizem não ambicionar, e descrevem pormenorizadamente sua chegada ao sindicato e aos referidos cargos. Como argumenta Bourdieu, "as mulheres tendem menos do que os homens a se atribuir as competências legítimas” (1995, p. 147). Vale a pena transcrever uma das falas, de uma informante que leva o equivalente a 7 páginas para explicitar sua aproximação ao sindicato e posterior participação na Diretoria do Núcleo:

"Aí um dia uma colega fez uma colocação que achava que eu tinha condições de assumir, aquilo até me deixou assim, de certa forma me envaideceu mas me deu uma angústia, eu ficava apavorada, mas eu não tenho, como é que eu vou estar falando em público, eu não sou de falar, não gosto, e eu também me lembrava, a imprensa, entrevista, rádio, televisão, ai! Enfim, foi assim, não sei que período foi aquilo, se foi um mês, quinze dias, mas que eu não dormia, eu vivia, eu já evitava vir às reuniões, eu já não vinha à reunião aqui para esquecerem de mim...".

Por fim, quanto à experiência das mulheres, várias destacam o "apoio" e o "estímulo" dos genitores do sexo masculino e de seus maridos e filhos (homens) na militância. Duas citam que seus pais as apoiavam por serem militantes de esquerda (antigo PTB, brizolista), enquanto, para outra, a situação era oposta, pois seu pai, militar, era completamente contrário à sua participação ${ }^{7}$. Com exceção de uma professora, não há menção às mães; e essa, quando o faz, afirma que "com o pai sentava e discutia... até com a mãe claro se conversava outras coisas, mas essa questão mais política era mais com ele...”.

Já um dos homens não evoca a família para abordar esse tema, enquanto o outro aduz a "compreensão" da mesma quanto às suas atividades militantes.

O segundo elemento a enfatizar, nesta seção, trata da importância da ação sindical na experiência profissional e na vida pessoal dos sujeitos. São uniformes quando argumentam que "o movimento sindical é uma pós-graduação de vida”, o que pode ser interpretado 
conforme os comentários a seguir. Primeiro, a atividade sindical forneceulhes uma visão de mundo e conhecimentos sobre a realidade social que não tinha, o que se reverte na educação de seus alunos, embora haja o receio de que a influência seja direta demais. Segundo, sublinham a qualificação do trabalho pedagógico como algo que justifica a luta sindical, criticando colegas que, por dizerem-se mal-pagos, não querem trabalhar. Por fim, evocam uma compreensão diferenciada da relação docente-aprendiz porque reconhecem que "a gente é um parceiro do crescimento dele, que a gente está ali pra contribuir pra que ele possa crescer, e não pra fiscalizar e pra estar xingando".

\subsection{Concepções sobre relações de gênero}

Neste trabalho, o conceito de gênero está sendo usado no sentido de acentuar "o caráter fundamentalmente social das distinções baseadas no sexo" (SCOTT, 1995, p. 72). Procura-se usá-lo como forma de compreender como essas construções culturais - justificadas por distinções biológicas - habitam o cotidiano das pessoas e em que medida são utilizadas como instrumentos nas disputas por poder social, político e econômico. Deste modo, nesta subseção serão desenvolvidos dois aspectos: como homens e mulheres interpretam as relações de gênero dentro do sindicato e que representações têm sobre gênero e trabalho docente.

\subsubsection{As relações de gênero no espaço de atuação sindical}

O principal objeto deste estudo foi o mais difícil de abordar durante as entrevistas. O que mais se destaca na manifestação das e dos entrevistados, quando se lhes pergunta sobre relações de gênero, é o rechaço inicial a assumir o tema como objeto de discussão. Há a tendência a interpretar o propósito das questões como investigação da existência de machismo e, baseados/as nessa premissa, ainda que as perguntas não mencionem nada parecido, rejeitam debater o tema. Essa rejeição foi mais evidente no caso de duas mulheres e dos dois homens, com graus diferentes, conforme a intervenção da entrevistadora conseguia esclarecer os propósitos da investigação.

Contudo, uma das mulheres vedou-se totalmente a tratar do assunto. Suas repetidas contestações foram: "não noto diferença", "não dou bola", "não observei", "não sei se eu não me importei ou se não existe mesmo". Uma segunda o faz, inicialmente, afirmando: "não tenho muita leitura da discussão", "posso até me contradizer". Os suspiros e as 
reticências, os "me parece, tá?", denotam desconforto, mas paulatinamente assume falar a respeito.

Os homens apressam-se a garantir a igualdade entre os sexos dentro do sindicato, no caráter de defensores de sua justiça e de testemunhas das capacidades das mulheres. Pelo raciocínio anterior, se a discussão não está muito presente no cotidiano, o fato de serem homens pode sugerir que seriam machistas e, como é natural, procuram deixar bem claro que não é verdade:

"Eu nunca vi assim um questionamento por parte de colegas homens do trabalho das mulheres dentro do sindicato e nem de forma pejorativa ou de brincadeira, nunca ouvi qualquer questionamento assim, qualquer brincadeira maldosa. Então acho que eu não vejo dentro do nosso sindicato esse problema até, pela presença maciça das mulheres em relação aos homens".

Afora isso, mal abordam as relações de gênero em educação, em termos de práticas pedagógicas ou outras circunstâncias nas quais o tema poderia ser tomado para reflexão.

A posição apresentada pelos homens sobre a capacidade das mulheres pode ser percebida a seguir:

"E no sindicato, eu vejo que a mulher ela é muito importante porque aí ela..., ela... amplia a dimensão da atividade da mulher dentro do próprio magistério, mostrando que além de professora ela pode ser uma liderança capaz de puxar uma luta, como nós temos o exemplo aí a professora Juçara Dutra Vieira mesmo, a nossa presidente do CPERS, é uma mulher extraordinária... uma pessoa dum equilíbrio e duma capacidade de administrar um... um sindicato incrível que eu não sei se teríamos algum homem capaz de fazer aquilo que ela fez mesmo. Então, mostra assim essa dimensão maior também da mulher não só de professora, de dona-de-casa, de pai e mãe que ela desenvolve, mas também de liderança política não é, no movimento sindical e no movimento político também..."

Aqui, é preciso sublinhar que devemos considerar a especificidade da atuação política desse grupo. Ele repete cinco pessoas da direção passada e as demais atuavam em outras instâncias do movimento. Isto é, eles e elas mantêm relações de companheirismo amplificadas pelo pertencimento à mesma corrente sindical.

Ademais, seu período de liderança tem sido de hegemonia feminina no CPERS/SINDICATO, situação diferenciada daquela vivida, em geral, em outras entidades. Rememorando alguns fatos, desde 1990 lembremos que a transformação da entidade em sindicato ocorreu em 1989 -, em quatro das cinco Diretorias, a presidência foi ocupada por 
mulheres ${ }^{8}$. Uma dessas, Lucia Camini, tornou-se, em 1999, Secretária de Educação no governo de Olívio Dutra e a professora que a substituiu, Juçara Dutra Vieira, foi reeleita duas vezes à presidência do CPERS e, atualmente, acumula o cargo de presidente da Confederação Nacional dos Trabalhadores em Educação (CNTE).

Ou seja, na memória de nossos sujeitos, o que podem evocar com mais força são líderes femininas. Só os mais velhos e/ou mais experientes têm recordações das lideranças masculinas, exatamente o oposto do que encontraram, por exemplo, Amado e Checa (1990), em seu estudo sobre a participação feminina no sindicato docente na Argentina, onde as próprias mulheres tinham dificuldade de enumerar personalidades femininas.

Mas isso não significa que não haja matizes em suas abordagens sobre as relações de gênero no sindicato. Tais aspectos transparecem mais nas falas de quatro das mulheres. Os itens indicados referem-se à existência de padrões diferenciados de comportamento e de compromisso de homens e mulheres com as tarefas sindicais e o trabalho docente propriamente dito.

Quanto à disponibilidade para a atividade sindical, elas fazem comentários sobre as maiores facilidades dos homens para militar, em virtude do tipo de compromisso familiar. O homem estaria mais liberado e citam vários casos de mulheres que só podem comparecer ao sindicato em horários que não atrapalhem o serviço doméstico ou não melindrem a vontade do marido. A forma como se manifestam varia segundo a informante. Umas falam conformadamente: faz parte do dia-a-dia das lutas das mulheres terem que se adaptar às dificuldades impostas a seu sexo. Um dos homens argumenta num sentido semelhante, adicionando que isso faz parte de um processo "natural de transição", de "mudanças de comportamentos".

Já outra sindicalista protesta veementemente, em várias passagens de sua entrevista, quanto a essa disponibilidade controlada: "é impressionante como há mulheres que estão militando porque os maridos deixam, porque os maridos compreendem, porque sabem que é um trabalho importante, mas desde que eu esteja no horário do almoço...”.

Contudo, o maior desembaraço dos homens não se traduziria em efetiva atividade, segundo a unanimidade das quatro mulheres. Todas reclamam que "as mulheres são mais envolvidas e se dedicam mais ao trabalho, ficamos mais tempo do que os próprios colegas de diretoria que temos hoje", mas curiosas são as maneiras utilizadas para explicar o 
fenômeno, sendo as sindicalistas cuidadosas em suas afirmações. Uma primeira acha "que o homem gostam mais de falar e a mulher é mais tarefeira mesmo...". Assim se refere outra, para a qual o comportamento masculino refletiria uma maior "objetividade”: “... aí entra assim aquela coisa do momento, ah, tem que organizar a sala, então chega, bota bandeirinha, não sei o quê, tirar fotografia e deu - e a gente fica com aquela, o antes, o durante, o depois". Para uma terceira, o comportamento masculino é qualificado de "menos tímido":

"No CPERS... o que a gente sente em relação aos homens aqui, que os homens não vão ficar bravos comigo, pelo amor de Deus, que as mulheres assumem mais que os homens, aqui no, no Núcleo sempre foi, nos outros núcleos eu não sei como é que é a realidade, mas aqui no nosso Núcleo sempre as mulheres assumiram mais...".

E embora reconheça que os homens são em menor número, diz que eles

"sempre ocupam os espaços, sempre falam tudo, a mas, a, a maioria das mulheres costuma sempre fazer avaliações também, e bem significativas,... a mulher tem mais a dificuldade de, de, de até de começar a falar, mas depois que começa, a mulher em geral assume mais que o homem...”.

Por fim, uma quarta indica que alguns dos homens com os quais milita "dependem de orientação nossa, das mulheres, nós ainda temos hegemonia total dentro do sindicato. Por contrapartida, todo o trabalho é feito por nós". Mas há quem reconheça essa situação como típica do CPERS, não ocorrendo na CUT, onde haveria mais resistência à militância de mulheres.

Pensando no conjunto das entrevistas, percebo que quase ninguém se referiu à sua própria identidade de gênero, a maioria apresentou representações sobre o outro sexo ou então se serviu de comparações, indicando diferenças. Quanto às distintas vivências da sexualidade, houve apenas uma breve menção, quando uma professora referiu-se aos preconceitos racistas e machistas de algumas docentes e suas conseqüências sobre a prática profissional. Continuarei a abordar isso a seguir.

\subsubsection{Representações sobre relações de gênero no trabalho docente e no trabalho pedagógico}

Tratemos, agora, das representações de gênero no trabalho docente. Poderíamos arrolar para a discussão, neste ponto, a produção e a reprodução de identidades de gênero na escola, por meio das práticas 
pedagógicas; pelo uso de materiais instrucionais que reforçam supostos papéis de gênero (e estimulam um padrão heterossexual); pela divisão sexual do trabalho na escola e na sociedade, o que implica o reconhecimento da generificação das ocupações, etc.

Embora tais aspectos estejam tão imiscuídos no cotidiano das organizações que nem chegam a ser perceptíveis, Carvalho indica que:

... estudos mostram que as relações de gênero não são simplesmente levadas prontas pelas pessoas para seu trabalho, mas são criadas, reafirmadas e transformadas pelos critérios de funcionamento das organizações, a hierarquia, as relações e as divisões de trabalho, concluindo que o discurso e a prática do trabalho são ao mesmo tempo constituintes das masculinidades e das feminilidades e por elas constituídos (1999, p. 14-15).

Mas, ao que parece, é difícil, para as pessoas entrevistadas, considerar a circulação de culturas que reforçam e/ou recriam padrões de gênero, porque pouco desenvolveram essas questões. Assim, frente à questão sobre diferentes experiências pedagógicas e/ou o relacionamento docente/alunado conforme se pertença a um ou outro sexo, novamente pode-se destacar que foram as referidas quatro mulheres que indicaram diferenças, enquanto os homens tendem a não percebê-las ou a não problematizá-las.

Um deles afirma que, no ensino fundamental, as meninas são muito próximas dos docentes homens, não encontrando, também, "dificuldades" na sua prática no ensino médio. Contudo, percebe dificuldades de alguns colegas "de lidar com isso, isso é, com o ensino fundamental", mas avalia "que aí seriam mais questões pessoais".

Nesse sentido, o segundo professor "confessa" que tem "dificuldades de trabalhar com crianças pequenas" - não se refere ao sexo -, e pensa que "é questão pessoal mesmo", gostando mais de trabalhar no noturno porque se "identifica" mais com quem "é mais vivido". Menciono essa informação considerando a idéia disseminada de que as mulheres estariam mais capacitadas para o trabalho com crianças pequenas.

Entre as entrevistadas, apenas uma indicou uma relação "mais à vontade" com os meninos do que com as meninas, o que explica por ter somente filhos homens.

No que tange ao trabalho docente propriamente dito, envolvendo práticas pedagógicas, ética e responsabilidade profissional, as quatro entrevistadas reclamam de posturas de colegas homens em suas escolas, bem como citam prováveis regalias que esses teriam. Para uma 
delas, as professoras seriam mais "competentes", "interessadas", "responsáveis", enquanto os professores "quase todos são relapsos". E isso porque

“... o professor, ele leva mais assim pro lado de bico, o magistério é até arrumar uma coisa melhor... Que a professora é mais acomodada com o salário e o professor não, o professor ele está sempre com aquela coisa assim de arrumar uma coisa que ele ganhe melhor".

Embora reconheça que há "professores que são pedagogicamente excelentes", uma segunda entrevistada assinala que

"a grande maioria que eu conheço são, eu não sei de onde saíram, eu não sei em que escola se prepararam, que o tratamento que eles têm com os alunos é um absurdo... Pedagogicamente nada, nada, nada, não se preocupa com nada, nada dentro da escola, dentro de uma sala de aula a não ser passar o tempo que ele tem que ficar ali dentro, o mais agradavelmente possível".

Por outra parte, esta é a única docente que analisa também comportamentos de professoras, indicando como os preconceitos racistas e machistas de algumas têm conseqüências sobre a prática docente. Assim, ela complementa:

"as mulheres são muito machistas e racistas, impressionante, é incrível isso aí. Os guris, os alunos que são bons, pra elas ali, têm tudo, as meninas que são boas que ótimo, se não é boa aluna ou se não se interessa e se é negra, tá fuzilada, se tem o aspecto muito ruim assim pronto, se uma menina tem, faz uma coisa lá, um tapa num, é machorra".

As mulheres igualmente assinalam os privilégios dos docentes, que estariam em contradição com seu suposto papel masculino, porque eles deveriam assumir certas tarefas e facilitar o trabalho feminino (como pegar os últimos horários do noturno e ajudar a fechar as escolas). Para uma delas, orientadora educacional, "os homens sempre procuram levar vantagem em cima das mulheres. Sempre os homens querem os melhores horários, os homens querem as melhores turmas...”.

E indicam o que pode conduzi-los a ser privilegiados - "não sei se por serem em menor número, acabam sendo protegidos pelas direções de escola" -, principalmente frente ao maior número de dirigentes masculinos num universo tão feminizado. Como resume uma delas:

“... normalmente nas escolas parece que há uma tendência de aceitar muito mais um dirigente do sexo masculino do que do sexo feminino porque as pessoas, quando vêem assim questões críticas em alguém..., são muito críticas vamos dizer assim com a colega mulher, né, do que com o homem”. 
Enquanto outra avalia que, havendo homem e mulher disputando, mesmo que a mulher seja mais competente, a opção é pelo homem, "por bobagem assim, ah, se a fulana for [eleita]... todo mundo tem que entrar na ordem... essas coisas assim, botando as coisas certas como um castigo...”. Em síntese: a mulher na direção exigiria mais da comunidade docente, portanto esta - composta por maioria feminina prefere que um homem assuma a direção.

Destaco uma fala de um dos docentes a respeito da autoridade ${ }^{10}$, para o qual

"nós temos professoras que se impõem bastante,... que dominam bem a classe e temos alguns homens que não têm esse domínio que muitas têm também, mas me parece assim no geral, acredito até que ainda se conserve um pouquinho mais... de respeito, de autoridade quando o professor é homem do que mulher... há professoras que realmente têm um domínio muito bom da turma e a gente ouve relatos de aluno da professora: ah, a professora é boa, ela cobra, ela é enérgica, ela é... se impõe enfim e tal”.

Mas esse informante atribui o "domínio", melhor dizendo, essa “aceitação do aluno" como "uma coisa muito particular de cada um”, já que nem todos/as teriam estratégias pedagógicas de cativar os alunos para melhor ensinar, discorrendo sobre o quanto essa temática deveria ser objeto dos cursos de formação docente.

Finalmente, há algo sobre o qual a posição das pessoas atravessa possíveis diferenças de gênero: a política de cotas para o preenchimento de cargos políticos e sindicais, sendo que as respostas também abordaram a reserva de vagas para negros/as no ensino superior. Considerando que a CUT, a que o CPERS/SINDICATO está filiado, determina cotas para suas diretorias, foi feita uma pergunta sobre opinião a respeito. Das quatro pessoas que se pronunciaram, há quatro respostas distintas, mas que acabam mesclando os mesmos argumentos: a crítica à discriminação e a defesa da capacidade da mulher.

Uma das sindicalistas é contrária, argumentando que todo mundo teria que conquistar espaço por mérito. Um dos homens diz que não tem idéia formada porque, até o momento, não encontrou consistência nas argumentações que já ouviu. $\mathrm{O}$ outro acha que não é contra, dado que, sendo a cultura da sociedade machista, a cota garante a participação feminina até que se dê "um passo maior, que é a garantia do espaço igual para todos, tanto homem como mulher". E a última mulher diz que, em princípio, é contra, embora seja um começo, especialmente no caso do racismo. E acrescenta: "se isso servir de estímulo pras mulheres 
reconhecerem que pelo fato de serem mulheres elas não são incompetentes, que elas têm valor e que podem fazer muitas coisas melhor que muitos homens, tá, aí vale, agora a obrigatoriedade de ter, eu acho horrível".

Como se percebe, o assunto é polêmico e ainda demanda muita discussão. De fato, as cotas só ganham sentido se tiverem, por trás da reivindicação, grupos de pressão que imprimam futuro a uma sociedade com menor grau de discriminação e desigualdade, seja em que esfera for, para além das cotas. Sobre isso se pronuncia Castro:

Hoje, mulheres sindicalistas e militantes concordam que a quota foi um passo importante para a visibilidade do não-representado, do não-dito, nas organizações sindicais e partidárias, mas que o lugar-posição não vem garantindo a representação/posição das mulheres administradoras, de uma perspectiva de gênero. Alerta-se que o compartilhamento do espaço em posições de comando pede que se acionem programas tais como de treinamento para as mulheres no plano das políticas de quadro e, para homens e mulheres, no plano de gênero, além de mudanças de práticas de ordenação da vida organizacional (1995, p. 36).

\section{EPÍLOGO}

Foram os resultados de uma investigação anterior a esta aqui relatada que me conduziram a aprofundar estudos sobre relações de gênero e educação. Focalizada nas concepções de experientes sindicalistas docentes a respeito do trabalho do professorado, surpreendi-me com a invisibilidade da feminização da categoria para sete de oito entrevistados - cinco mulheres e três homens de distintos espectros ideológicos. Somente uma das mulheres não desenvolveu um discurso no qual preponderava a idéia de neutralidade de gênero do trabalho docente. Por isso, passei a questionar: como é possível que informantes-chave tivessem tal grau de distanciamento de um problema tão presente no referencial do qual eu fazia uso?

De fato, embora com todas as limitações evocadas anteriormente, incluindo sua pouca abundância, creio que se pode afirmar a existência de produção - em diferentes vertentes e focos de análise - que leva em conta a importância das relações de gênero em educação. Têm sido examinadas, assim, as práticas pedagógicas e as trajetórias de formação, as representações de gênero dentro da instituição escola, dos currículos e materiais instrucionais, a história da educação a partir de uma leitura de gênero. Contudo, é possível afirmar que esses achados não tiveram, ainda, repercussão suficiente sobre os currículos de formação docente e no que tange à agenda de sindicatos de trabalhadores/as em educação, lacuna que deveria ser superada o mais rapidamente possível. 
Se concordarmos que as representações da docência não são intrínsecas às qualidades ou condições do professorado, sendo, sim, criações no campo da cultura, muito poderemos aprofundar no debate sobre a mesma. Por exemplo, não é preciso apenas lamentar as conseqüências da feminização para uma possível desqualificação do trabalho docente, como indicam estudos da sociologia das profissões para os quais quanto mais feminizado, mais proletarizado se encontra um ofício (GUERRERO SERÓN, 1996). Ao contrário, podemos positivar a atuação de professores e professoras, descobrir características nesse trabalho que são inovadoras e/ou que não se sujeitam aos estereótipos.

Ao não associar, assim, a feminização a um processo no qual o ofício necessariamente sofreu perda de qualificações, quem sabe pudéssemos perceber, nele, a invenção de outras concepções de trabalho. Não necessariamente as mulheres tornaram-se vítimas por conformarem em maioria o corpo professoral, já que a feminização deste possibilitou tanto uma das saídas das mulheres ao espaço público das sociedades, quanto que crianças vissem mulheres adultas não apenas como mães, mas também como profissionais. Ademais, a idéia da docência como "cuidado dos outros" pode não ser uma atribuição exclusiva das mulheres; talvez muitos professores compartilhem desse tipo de comportamento.

Quanto ao objeto deste trabalho, algumas informações obtidas na pesquisa são significativas. Fica evidente que, tal como no ambiente educacional, no ambiente sindical circulam representações dicotômicas, diferenciando o comportamento masculino do feminino, com valorização do primeiro. São dicotômicas, também, porque não se admite que haja diferentes formas de masculinidade ou feminilidade. $O$ masculino é tomado como o neutro, como aquele que deveria ser, e quando algumas mulheres conseguem aproximar-se deste padrão esse fato chama a atenção e aparece como justificativa do potencial das mulheres. Essa sutil armadilha da linguagem ocorre, por exemplo, quando as e os entrevistados são convidados a falar sobre diferentes práticas pedagógicas conforme o sexo do/da docente. Um item indicado refere-se à disciplina, quando se afirma que muitas professoras alcançam disciplina em classe, "conseguem se impor", sendo elogiadas por isso. Outro aspecto trata das preferências por professores diretores, não tanto porque teriam mais capacidade para essa atividade - admite-se a capacidade das mulheres -, mas porque os homens são "por natureza" mais respeitados, o que torna mais conveniente colocar homens no cargo. 
Sobre isso podemos recuperar a necessidade de estimular o alcance, pelas mulheres, de tecnologias do poder, num sentido foucaultiano, ou de auto-atribuição de competências sociais, nas palavras de Bourdieu, para que ganhem segurança na busca da eqüidade. Por outra parte, no caso em questão, o acompanhamento das narrativas das entrevistadas não permite vê-las como vítimas: ao contrário, a atividade sindical pode ser encarada como um motor para o fortalecimento das mulheres nos espaços públicos. São perceptíveis, sim, diferenças no engajamento e na participação, mas sem que se possa deduzir daí nenhum grau de subordinação.

Para finalizar, é possível lançar tópicos a serem abordados futuramente. Entre eles, por exemplo, poderíamos indagar que implicações possíveis sobre o cotidiano dos sindicatos e das escolas surgem do fato de que os homens estejam sobre-representados nos cargos dirigentes. Poderíamos questionar a (in)existência de atuação do sindicato em torno das questões de gênero junto à sua base e as conseqüências disso também sobre as práticas escolares. Por fim, um aspecto metodológico a considerar, no plano da análise das representações, é se a diferença numérica entre homens e mulheres nas diretorias das entidades permite, com suficiência, que se vislumbrem diferenças nas representações segundo o sexo. Sobre isso já está em execução projeto que pretende, junto à mesma seção sindical analisada, entrevistar membros ligados à totalidade das suas gestões diretivas (a partir de 1980). Mas isso já é uma outra história.

\section{REFERÊNCIAS}

ALMEIDA, Jane S. de. Ler as letras: por que educar meninas e mulheres? São Bernardo do Campo/Campinas: Universidade Metodista de São Paulo/Autores Associados, 2007. ALMEIDA, Jane S. Mulher e educação: a paixão pelo possível. São Paulo: UNESP, 1998.

ALVES, J. E. D. A participação da mulher na ANDES-SN. Universidade e Sociedade, Brasília, n. 18, p. 96-102, mar. 1999.

AMADO, Ana; CHECA, Susana. Participación sindical femenina en Argentina; sindicato docente un estudio de casos. Buenos Aires: Instituto Latinoamericano de Estudios Transnacionales (ILET), 1990. (Mimeogr.)

APPLE, Michael. Relações de classe e de gênero e modificações no processo do trabalho docente. Cadernos de Pesquisa, São Paulo, n. 60, p. 3-14, fev. 1987.

ARAÚJO, Helena C.G. As mulheres professoras e o ensino estatal. Educaşão \& Realidade, Porto Alegre, v. 16, n. 2, p. 45-57, jul./dez. 1990.

BOURDIEU, Pierre. A dominação masculina. Educaşão \& Realidade, Porto Alegre, v. 20, n. 2, p. 133-184, jul./dez. 1995.

BOURDIEU, Pierre. Ao leitor. In: BOURDIEU, Pierre (Coord.). A miséria do mundo. Petrópolis: Vozes, 1997. p. 9-10. 
BOURDIEU, Pierre. La distinción; criterio y bases sociales del gusto. Madrid: Taurus, 1999.

BRUSCHINI, Cristina. Desigualdade de gênero no mercado de trabalho brasileiro: o trabalho da mulher no Brasil e nas regiões Nordeste e Sudeste na década de oitenta. In: LIGOCKI, M. S.; LIBARDONI, M. (Coords.). Discriminação positiva, ações afirmativas; em busca da igualdade. 2 ed. São Paulo: CFEMEA/ELAS, 1996. p. 87-118.

BRUSCHINI, Cristina; AMADO, Tina. Estudos sobre mulher e educação: algumas questões sobre o magistério. Cadernos de Pesquisa, São Paulo, n. 64, p. 4-13, fev. 1988.

CAPPELLIN, Paola. Viver o sindicalismo no feminino. Estudos Feministas, Rio de Janeiro, número especial, p. 271-290, 1994.

CARVALHO, Marília. Ensino: uma atividade relacional. Trabalho apresentado na $22^{\mathrm{a}}$ Reunião Anual da ANPEd, 1999, Caxambu.

CARVALHO, Marília. Vozes masculinas numa profissão feminina: o que têm a dizer os professores. Estudos Feministas, Florianópolis, v. 6, n. 2, p. 406-422, 1998.

CASTRO, Mary. Gênero e poder no espaço sindical. Estudos Feministas, Rio de Janeiro, v. 3, n. 1, p. 29-51, 1995.

COMISIÓN ECONÓMICA PARA AMÉRICA LATINA Y EL CARIBE. Participación, liderazgo y equidad de género en América Latina y el Caribe. Santiago de Chile, CEPAL, 1999. (Mimeogr.).

CONNELL, Robert. Políticas da masculinidade. Educação \& Realidade, Porto Alegre, v. 20, n. 2, p. 185-206, jul./dez. 1995.

COSTA, Marisa V. O magistério e a política cultural de representação e identidade. In: BICUDO, Maria Aparecida e SILVA JR., Celestino (Orgs.). Formação do educador e avaliação educacional. São Paulo: UNESP, 1999. v. 3. p. 117-136.

DELGADO, Maria Berenice. Mulheres na CUT: um novo olhar sobre o sindicalismo. In: BORBA, Ângela; FARIA, Nalu; GODINHO, Tatau (Orgs.). Mulher e política; gênero e feminismo no Partido dos Trabalhadores. São Paulo: Fundação Perseu Abramo, 1998. p. 209-224.

FERNÁNDEZ ENGUITA, Mariano; SAN ROMÁN GAGO, Sonsoles. Los efectos imprevistos de la feminización del magisterio: sugerencias para la investigación. Cadernos de Educação, Pelotas, n. 17, p. 9-32, jul./dez. 2001.

FERREIRA, Márcia O. V. As contribuições da pesquisa sobre a profissão docente para a compreensão do futuro da docência: algumas perspectivas de estudos no caso brasileiro. In: LAMPERT, Ernâni (Org.). Educação na América Latina; encontros e desencontros. Pelotas: EDUCAT, 2002. p. 231-259.

FERREIRA, Márcia O. V. Docentes, representações sobre relações de gênero e conseqüências sobre o cotidiano escolar. In: SOARES, Guiomar; SILVA, Méri Rosane; RIBEIRO, Paula (Orgs.). Corpo, gênero e sexualidade: problematizando práticas educativas e culturais. Rio Grande: FURG, 2006. p. 69-81.

FERREIRA, Márcia O. V. Mulheres e homens em sindicato docente: um estudo de caso. Cadernos de Pesquisa, São Paulo, v. 34, n. 122, p. 391-410, maio/ago. 2004.

FULLER, Norma. La constitución de la identidad de género entre varones urbanos del Perú. In: VALDÉS, Teresa; OLAVARRÍA, José (Eds.). Masculinidad y equidad de género en América Latina. Santiago: FLACSO-Chile, 1998. p. 56-68.

GIULANI, Paola. Os movimentos de trabalhadoras e a sociedade brasileira. In: PRIORE, Mary Del (org.). História das mulheres no Brasil. 5 ed. São Paulo: UNESP/Contexto, 2001. p. 640-667. 
GONÇALVES, Luiz A.; GONÇALVES e SILVA, Petronilha. O jogo das diferenças; o multiculturalismo e seus contextos. Belo Horizonte: Autêntica, 1998.

GUERRERO SERÓN, Antonio. La profesión docente: asociacionismo y feminización. In: GUERRERO SERÓN, Antonio. Manual de sociología de la educación. Madrid: Síntesis, 1996. p. 193-207.

HALL, Stuart (Ed.). Representation: cultural representations and signifying practices. Sage, 1997.

HUMPHREY, John. Sindicato; um mundo masculino. Novos Estudos Cebrap, São Paulo, v. 2, n. 1, p. 47-52, abr. 1983.

HYPOLITO, Álvaro. Trabalho docente, classe social e relações de gênero. Campinas: Papirus, 1997.

KIMMEL, Michael S. El desarrollo (de género) del subdesarrollo (de género); la produccón simultánea de masculinidades hegemónicas y dependientes en Europa y Estados Unidos. In: VALDÉS, Teresa; OLAVARRÍA, José (Eds.). Masculinidad y equidad de género en América Latina. Santiago: FLACSO-Chile, 1998. p. 207-217.

LOURO, Guacira. Mulheres na sala de aula. In: DEL PRIORE, Mary (Org.). História das mulheres no Brasil. 5 ed. São Paulo: UNESP/Contexto, 2001. p. 443-481.

NÓVOA, António. Para o estudo sócio-histórico da gênese e desenvolvimento da profissão docente. Teoria \& Educação, Porto Alegre, n. 4, p. 109-139, 1991.

PARKIN, Frank. Marxismo y teoría de clases: una crítica burguesa. Madrid: Espasa-Calpe, 1984.

PINTO, Céli Regina J. Uma bistória do feminismo no Brasil. São Paulo: Fundação Perseu Abramo, 2003.

ROSEMBERG, Fúlvia. Caminhos cruzados: educação e gênero na produção acadêmica. Educação e Pesquisa, São Paulo, v. 27, n. 1, p. 47-68, jan./jun. 2001.

ROSEMBERG, Fúlvia; AMADO, Tina. Mulheres na escola. Cadernos de Pesquisa, São Paulo, n. 80, p. 62-74, fev. 1992.

SARTORI, Ari. Homens e relações de gênero entre sindicalistas de esquerda em Florianópolis. In: BRUSCHINI, Cristina; PINTO, Céli (Orgs.). Tempos e lugares de gênero. São Paulo: Fundação Carlos Chagas/Editora 34, 2001. p. 216-239.

SCOTT, Joan. Gênero: uma categoria útil de análise histórica. Educação \& Realidade, Porto Alegre, v. 20, n. 2, p. 71-99, jul./dez. 1995.

SILVA, Tomaz Tadeu da. O currículo como fetiche; a poética e a política do texto curricular. Belo Horizonte: Autêntica, 1999.

SILVA, Tomaz Tadeu da. Identidades terminais: as transformações na política da pedagogia e na pedagogia da política. Petrópolis: Vozes, 1996.

SILVA, Tomaz Tadeu da. A produção social da identidade e da diferença. In: SILVA, Tomaz Tadeu da (Org.). Identidade e diferença; a perspectiva dos Estudos Culturais. Petrópolis: Vozes, 2000. p. 73-102.

SIMPSON, Richard; SIMPSON, Ida H. Las mujeres y la burocracia en las semiprofesiones. In: FERNÁNDEZ ENGUITA, Mariano (Ed.). Sociología de la educación. Barcelona: Ariel, 1999. p. 350-377.

SOUZA-LOBO, Elisabeth. A classe operária tem dois sexos; trabalho, dominação e resistência. São Paulo: Brasiliense, 1991.

TAMBARA, Elomar. Profissionalização, escola normal, feminização e feminilização: magistério sul-rio-grandense de instrução pública - 1880/1935. In: HYPOLITO, Álvaro; VIEIRA, Jarbas; GARCIA, Maria Manuela (Orgs.). Trabalho docente: formação e 
dentidades. Pelotas: Seiva, 2002. p. 67-97.

VIANNA, Cláudia. Magistério paulista e transição democrática; gênero, identidade coletiva e organização docente. Revista Brasileira de Educação, São Paulo, n. 3, p. 75-85, set./dez. 1996.

VIANNA, Cláudia. A produção acadêmica sobre organização docente: ação coletiva e relações de gênero. Educação \& Sociedade, n. 77, p. 100-130, dez. 2001.

VILLELA, Heloísa. O mestre-escola e a professora. In: LOPES, Y.; FARIA FILHO, L. e VEIGA, C. (Orgs.). 500 anos de educação no Brasil. 2 ed. Belo Horizonte: Autêntica, 2000. p. 95-134.

WEBER, Max. Economia e sociedade; fundamentos da sociologia compreensiva. 3 ed. Brasília: UnB, 1994. v. 1.

\section{NOTAS}

${ }^{1}$ Versão ampliada de trabalho apresentado na $27^{\text {a }}$ Reunião Anual da ANPEd Associação Nacional de Pós-Graduação e Pesquisa em Educação (Caxambu, 21 a 24/11/2004). Agradeço ao CNPq e à UFPel pela concessão de bolsas de Iniciação Científica; às componentes de minha equipe de trabalho na ocasião: Profa s Ana Helena Beckenkamp, Jenice Tasqueto de Mello e Raquel Perpétua Paré da Costa (voluntárias); e acadêmicas bolsistas Adélia Porto de Souza e Marcele Volcan de Matos; ao CPERS/SINDICATO; ao Prof. Álvaro Hypolito e, especialmente, aos entrevistados e entrevistadas, a quem dedico a epígrafe de Bourdieu.

${ }^{2}$ Veja-se Weber (1994), especialmente no primeiro capítulo da Primeira Parte o parágrafo 10 ("Relações abertas e relações fechadas") e no segundo capítulo da Segunda Parte o parágrafo 2 ("Relações econômicas 'abertas' e 'fechadas"').

${ }^{3} \mathrm{O}$ motivo pelo qual tomo o livro da autora em questão é porque ele, obra póstuma, reúne textos escritos em diferentes momentos e para diversas ocasiões, revelando as respostas que essa intelectual e militante feminista brasileira dava à discussão realizada no âmbito das ciências sociais e dos movimentos sociais sobre o tema do trabalho da mulher e das relações de gênero. É possível, assim, perceber, pela leitura de seus vários capítulos, quais eram as problemáticas mais significativas nas esferas citadas, ao menos a partir dos anos 1970.

${ }^{4}$ No livro citado, Souza-Lobo indica uma versão mimeografada do conhecido texto de Scott. De fato, na primeira publicação dele aparece uma nota esclarecedora, no pé de página. Abrindo o texto, diz Scott: “... It was first prepared for delivery at the meeting of the American Historical Association in New York City, December 27, 1985” (p. 1053). Veja-se: SCOTT, Joan W. Gender: A Useful Category of Historical Analysis. The American Historical Review, v. 91, n. 5 (Dec., 1986), p. 1053-1075.

${ }^{5}$ Não se deve abandonar, contudo, a idéia de que os corpos são sexuados, e é neles que se exercem, e são eles que exercem, também, as relações de poder, por meio das práticas sociais. Conforme: Bourdieu, 1995.

"Apresenta outro tipo de "política" para a qual não haveria um nome conveniente, "uma vez que envolve uma tentativa para escapar de uma identidade de gênero e não para afirmá-la” (1995, p. 196).

${ }^{7}$ Pela idade das informantes, sua participação começa durante a ditadura militar brasileira. 
${ }^{8}$ Situação oposta deu-se de 1975 a 1990 . Nessas cinco gestões, o cargo de presidente uma vez foi ocupado por mulher e as demais vezes por homens. Veja-se Ferreira (2004).

${ }^{9}$ Não houve indução à resposta.

${ }^{10}$ Sobre a maior facilidade dos docentes homens para impor autoridade, diz Carvalho (1998) que, embora esse seja um aspecto recorrente nos estudos a respeito, "minhas observações têm indicado que controle, autoridade e punição sobre as crianças não parecem alheios ou contraditórios com práticas de cuidado ou ameaçadores à feminilidade das professoras primárias brasileiras".

Recebido: 22/03/07

Aprovado: 20/12/07

Contato:

Rua 15 de Novembro, 155

Centro

Cidade: Pelotas-RS

BRASIL

CEP: 96015-000

E-mail:marciaof@ufpel.edu.br 